\title{
Influence of Mineral Additions in the Inhibition of Delayed Ettringite Formation in Cement based Materials - A Microstructural Characterization
}

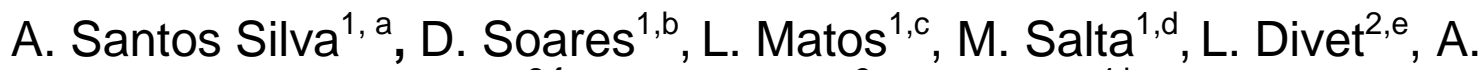 \\ Pavoine $^{2, f}$, A. Candeias ${ }^{3, g}$, J. Mirão ${ }^{4, h}$ \\ ${ }^{1}$ LNEC, Materials Department, Laboratório Nacional de Engenharia Civil, Av. Brasil 101, 1700- \\ 066 Lisboa, Portugal \\ ${ }^{2}$ LCPC, Service for Physico-Chemistry of Materials, Laboratoire Central des Ponts et \\ Chaussées, 58, Boulevard Lefebvre, 75732 Paris Cedex 15, France \\ ${ }^{3}$ University of Évora, Chemistry Department and Évora Chemistry Center, University of Évora, \\ Rua Romão Ramalho 59, 7000-671 Évora, Portugal \\ ${ }^{4}$ University of Évora, Department of Geosciences and Geophysics Center of Évora, University of \\ Évora, Rua Romão Ramalho 59, 7000-671 Évora, Portugal

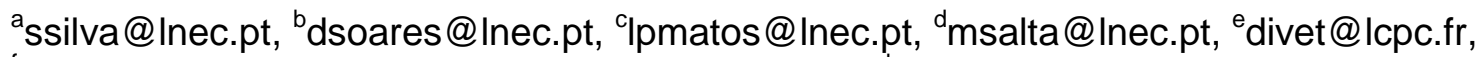 \\ fAlexandre.Pavoine@lcpc.fr, ${ }^{9}$ candeias@uevora.pt, himirao@uevora.pt
}

Keywords: DEF, SEM, Fly Ash, Metakaolin, Blast-Furnace Slag, Silica Fume, Limestone Filler.

\begin{abstract}
The degradation of concrete structures caused by delayed ettringite formation (DEF) is a problem that affects many concrete structures worldwide [1]. This pathology is due to the formation of expansive ettringite inside the material and is very difficult to deal with, because presently there is no efficient method to repair concrete structures affected by DEF. Hence, there is an urgent need to find preventive methods that may enable the inhibition of DEF in new constructions.

This paper presents the findings of a long-term study [2,3] on the expansion rate and microstructure of heat-cured concretes with different amounts of mineral additions, like fly ash, metakaolin, ground granulated blast-furnace slag, silica fume and limestone filler. For this purpose different concrete compositions were produced using the same binder, water/binder (w/b) ratios and aggregate type. The concretes were prepared and subjected to a heat-curing cycle and subsequently to two drying-humidification cycles. After these cycles the concrete specimens were immersed in water for long-term storage at $20 \pm 2^{\circ} \mathrm{C}$. Length changes of specimens were measured at regular intervals. The microstructures of old heat curing specimens were investigated by optical microscopy and SEM-EDS analysis. The results of the blendedconcrete compositions were compared with control compositions, and the conclusions were extracted.
\end{abstract}

